\title{
Contact damage of hard and brittle thin films on ductile metallic substrates: an analysis of diamond-like carbon on titanium substrates
}

\author{
D. Bernoulli $\cdot$ A. Wyss $\cdot$ R. Raghavan \\ K. Thorwarth $\cdot$ R. Hauert $\cdot$ R. Spolenak
}

Received: 22 October 2014/Accepted: 31 December 2014/Published online: 27 January 2015

(C) Springer Science+Business Media New York 2015

\begin{abstract}
Friction and wear minimizing coatings are crucial for applications in combustion engines and medical implants. Their performance is typically limited by mechanical failure especially due to local overload. In this work, the contact damage creation, evolution, and final morphology of hydrogenated diamond-like carbon (DLC)coated titanium (Ti) substrates are investigated. The influence of the DLC film thickness and the elastic-plastic deformation of the $\mathrm{Ti}$ on the contact damage are studied by microindentation and static finite-element analysis. Film thickness, indenter radius, and applied load as well as the elastic-plastic deformation of the Ti are shown to significantly affect contact damage. A failure plot is presented with the location of first failure in the DLC and compared to the experimental observation. In addition, a case study with variable fracture toughness of the DLC and its influence on the failure plot is shown. The stress distribution in the DLC follows a transition from a membrane-like to a
\end{abstract}

D. Bernoulli and A. Wyss have contributed equally to the work and are therefore shared first-authors.

D. Bernoulli · A. Wyss · R. Spolenak ( $₫)$

Laboratory for Nanometallurgy, Department of Materials, ETH

Zurich, Vladimir-Prelog-Weg 5, 8093 Zurich, Switzerland

e-mail: ralph.spolenak@mat.ethz.ch

D. Bernoulli

e-mail: daniel.bernoulli@mat.ethz.ch

A. Wyss

e-mail: andi.wyss@mat.ethz.ch

R. Raghavan

Laboratory for Mechanics of Materials and Nanostructures,

Empa, Swiss Federal Laboratories for Materials Science and

Technology, Feuerwerkstrasse 39, 3602 Thun, Switzerland

e-mail: r.raghavan@mpie.de plate-like deformation behavior upon increasing the DLC film thickness. Thin DLC films reveal increased cracking in the inner zone of the indent, while thicker DLC films reveal pronounced edge cracking. These edge cracks were correlated to pop-ins in force-displacement curves upon microindentation. Finally, a film thickness optimization process is presented for hard and brittle films on soft and ductile metallic substrates.

\section{Introduction}

Due to the high hardness, wear resistance and chemical inertness hydrogenated diamond-like carbon (DLC) films are widely used in industrial applications as protective coatings and sliding partners [1-4]. The usability of such DLC films is, however, strongly dependent on the resistance against contact damage $[5,6]$ which is created by high local pressure and can be induced by wear particles trapped between the sliding partners. The resistance against contact damage is affected by the stiffness of the substrate material

\section{Present Address:}

\section{R. Raghavan}

Structure and Nano-/Micromechanics of Materials, Max-PlanckInstitute für Eisenforschung $\mathrm{GmbH}$, Max-Planck-Strasse 1, 40237 Düsseldorf, Germany

K. Thorwarth · R. Hauert

Empa, Swiss Federal Laboratories for Materials Science and Technology, Überlandstrasse 129, 8600 Dübendorf, Switzerland e-mail: kerstin.thorwarth@empa.ch

R. Hauert

e-mail: roland.hauert@empa.ch 
and the DLC film thickness as it was shown on rather hard and stiff substrate materials like $\mathrm{Si}$, soda lime glass, and steel [7-10]. However, in the case of a soft and ductile metallic substrate such as titanium (Ti), contact damage is induced by prior plastic deformation of the substrate. Firstly, this phenomenon can be delayed by increasing the thickness of the DLC film which then shields the substrate from the stress field of the contact $[9,11]$. Secondly, the fracture strength of the DLC layer itself is also film thickness dependent [12] which influences its fracture behavior upon loading. Thus, in this study, the influence of the DLC film thickness and the elastic-plastic deformation of the substrate on the contact damage are investigated using hard DLC films on ductile Ti substrates. Although the study here is DLC on Ti, this analysis can be regarded as a model system of hard and brittle films on ductile metallic substrates. The general approach and methods presented in this work to analyze contact damage can therefore be applied to any hard material attached to a ductile metallic substrate.

\section{Experimental}

Contact damage was investigated by instrumented microindentation as well as by static finite-element analysis (FEA). The FEA, uniaxial loading, and microindentation procedure are presented hereafter.

FEA and uniaxial loading

Static FEA was performed with the commercially available FE software Comsol ${ }^{\circledR}$ (version 4.3). A spherical indenter with radius of $10 \mu \mathrm{m}$ was pressed into the DLC-Ti structure with a maximum load of $500 \mathrm{mN}$ acting normal to the surface with DLC film thicknesses varying from 50 up to $10 \mu \mathrm{m}$. In the FEA, an axially symmetric contact pair model was used. The meshing was optimized for processing time without information loss in the output quality i.e., the mesh density was sufficiently detailed to capture the relevant stress variations. The mesh was therefore fine near the contact problem (close to the indent) and loose far away from the contact problem (e.g., in the Ti substrate far away from the DLC film) as it is shown in Refs. [11, 13]. Fixed constraints were used for the nodes on the sides and bottom of the system. The DLC was considered as fully elastic, while the Ti substrate deformation was considered as elastic-plastic. The output data of the FEA are radial stresses $\left(\sigma_{\text {radial }}\right)$ for the DLC and von Mises principal stresses ( $\left.\sigma_{\text {vonMises }}\right)$ for the Ti substrate. These output data are selected because upon contact damage, crack formation in the DLC originates from radial stresses (see e.g., [8] among others), while the von Mises criterion for the Ti substrates allows the determination of the yielding. Hence, with these FEA output data, not only the stress generation upon contact damage can be quantified, but also a failure criterion can be additionally implemented which will be presented in the discussion.

Since the Ti substrate deforms elastic-plastically, the input data for the FEA were determined by uniaxial loading as reported in [12]. The uniaxial loading experiment was performed with a microtensile machine (Kammrath \& Weiss Dortmund, Germany) and a 0.4-mm-thick dogboneshaped Ti grade 4 substrate which was tested with a strain rate of $5 \times 10^{-5} \mathrm{~s}^{-1}$ to fracture. The load-displacement curves were recorded and from the known geometry converted into an engineering stress-strain curve. The stressstrain curve was then modeled by two linear fits: the first fit covered the elastic part, while the second fit describes the plastic part with the isotropic tangent modulus $\left(E_{\text {Tiso }}\right)$.

\section{Microindentation}

DLC films with thicknesses of 50, $500 \mathrm{~nm}, 1$, and $1.5 \mu \mathrm{m}$ were deposited by plasma-activated chemical vapor deposition (PACVD) with acetylene $\left(\mathrm{C}_{2} \mathrm{H}_{2}\right)$ as precursor gas and a self-bias of $-600 \mathrm{~V}$ on previously grinded and polished $\mathrm{Ti}$ grade four substrates with an average surface roughness of $3 \mathrm{~nm}$ (measured by atomic force microscopy). A more detailed description of the deposition process is provided in [13]. The DLC films in this study exhibit an intrinsic stress $\left(\sigma_{\text {res }}\right)$ of $-3.8 \pm 0.3 \mathrm{GPa}$ and a hardness of $23 \mathrm{GPa}$ as determined in [13] for the same type of DLC deposited on the same deposition machine and using identical deposition parameters. In addition, a Young's modulus $\left(E_{\mathrm{DLC}}\right)$ of $175 \mathrm{GPa}$ was determined using a Hysitron nanoindenter (Minneapolis, MN, USA). Contact damage was induced using a MTS Nanoindenter XP from Agilent Technologies (Santa Clara, CA, USA) equipped with a $10 \mu \mathrm{m}$ spherical diamond indenter from Synton (Nidau, Switzerland). The loading and unloading rate was set at $1 \mathrm{mN} \mathrm{s}^{-1}$, and a peak holding time of $5 \mathrm{~s}$ was used. Loads from 80 to $500 \mathrm{mN}$ were applied and load-displacement curves were recorded. Surface damage was analyzed using a LEO scanning electron microscope (Carl Zeiss, Germany) with a Gemini field emission column, operating at $5 \mathrm{keV}$ acceleration voltage, a base pressure of $10^{-6}$ mbar and a working distance of $3 \mathrm{~mm}$. The secondary electrons were detected with an in-lens detector. Crosssectional analysis was carried out with a Helios Nanolab 600i focus ion beam (FIB) using a $30 \mathrm{kV}$ gallium ion beam for material removal. Prior to cross-sectioning platinum, cover layers were deposited on the imprint.

\section{Results}

Uniaxial loading and FEA

The Ti substrate was tested by uniaxial loading to derive the stress-strain curve as input data for the FEA analysis. 


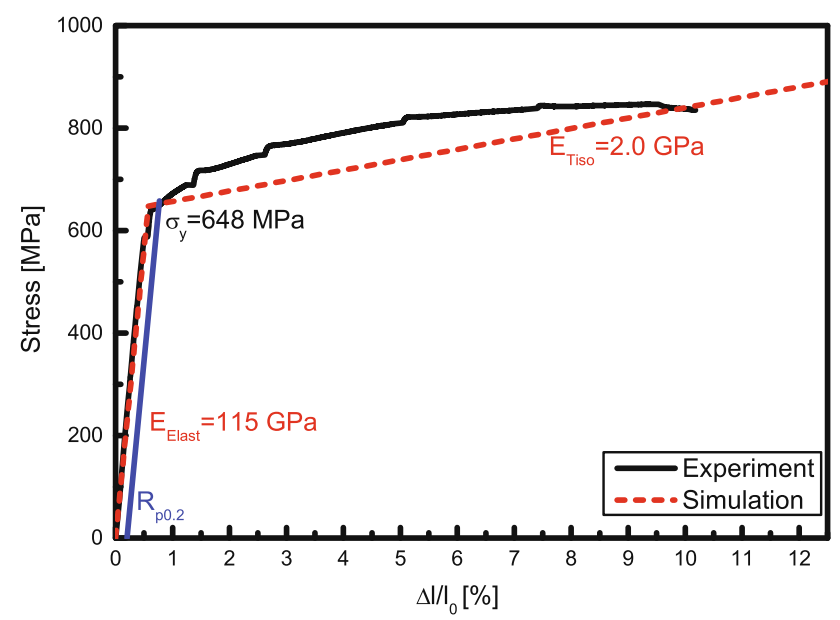

Fig. 1 Experimental and fitted stress-strain curve of Ti with linear fits for the elastic and plastic part. A $0.2 \%$ offset yield strength $\left(R_{\mathrm{p} 0.2}\right)$ was used for the yield point determination. The Ti substrate shows a yield strength of $\sigma_{\mathrm{y}}$ of $648 \mathrm{MPa}$, an elastic modulus $\mathrm{E}_{\text {Elast }}$ of $115 \mathrm{GPa}$, and the isotropic tangent modulus $E_{\text {Tiso }}$ is equal to $2.0 \mathrm{GPa}$

Two linear fits were applied to describe the elastic and the plastic part in the engineering stress-strain curve (Fig. 1). With the first linear fit for the elastic part and an offset yield strength of $0.2 \%\left(R_{\mathrm{p} 0.2}\right)$, a yield stress $\sigma_{\mathrm{y}}$ of $648 \mathrm{MPa}$ and a Young's modulus $E_{\text {Elast }}$ of $115 \mathrm{GPa}$ were determined, while the second linear fit for the plastic part revealed an isotropic tangent modulus $E_{\text {Tiso }}$ of $2.0 \mathrm{GPa}$. These values and the Young's modulus of the DLC film were implemented in the FEA model.

Upon simulated indentation with FEA, three different locations in the DLC exhibiting high tensile stresses were observed as shown for a $500 \mathrm{~nm}$ DLC film at $150 \mathrm{mN}$ in Fig. 2: The first location, indicated by zone 1 in Fig. 2 (called interface center), is at the interface of the DLC film and Ti substrate. The second location is at the contact zone of indenter and surface (zone 2 in Fig. 2, called surface center) where the indenter contacts the DLC and the third location (zone 3 in Fig. 2, called edge) where failure is prone to happen is at the edge of the indent where radial tensile stresses are generated. Plots as shown in Fig. 2 were created for film thicknesses varying between $50 \mathrm{~nm}$ and $10 \mu \mathrm{m}$ and with a maximum load of $500 \mathrm{mN}$. From these plots, the following trends were observed:

- The stresses at the surface center are compressive for low loads and turn into tensile stresses by increasing the load.

- With increasing film thickness, the load needs to be applied to turn the surface center stresses from compressive into tensile increases.

- Above a film thickness of $1 \mu \mathrm{m}$, the stresses at the surface center are still compressive even at the highest applied load.

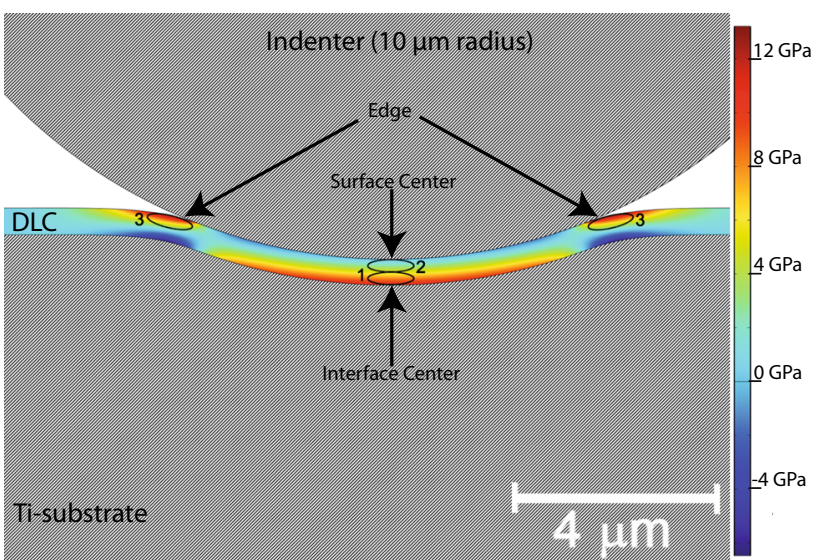

Fig. 2 Simulated stress distribution at a film thickness of $500 \mathrm{~nm}$ and a load of $150 \mathrm{mN}$ with the three-numbered stress intense locations. Location 1 is underneath the indenter at the interface DLC-Ti and called interface center; location 2 (called surface center) is in the center of the indent at the surface of the DLC film; and location 3 (called edge) is at the edge of the indent

- At the interface center and the edge zones, tensile stresses are observed regardless of the indentation depth.

\section{Microindentation}

Experimental contact damage as induced by loads ranging from 80 to $500 \mathrm{mN}$ in DLC of film thicknesses varying from $50 \mathrm{~nm}$ up to $1.5 \mu \mathrm{m}$ is shown in Fig. 3.

Figure 3 reveals that the final contact damage morphology changes significantly with applied load and film thickness. At loads of 80 and $150 \mathrm{mN}$, the diameter of the indent increases with decreasing film thickness which is not anymore the case for higher loads, indicating that in this high load regime, most of the deformation is localized in the substrate and cannot be shielded by the DLC film. At a load of $150 \mathrm{mN}$ and DLC film thicknesses of $500 \mathrm{~nm}, 1$, and $1.5 \mu \mathrm{m}$, the first circumferential cracks (which are from now on called edge cracks) are clearly visible, and their number increased with increasing load and thickness. Such a behavior was, however, not observed for the $50 \mathrm{~nm}$ DLC film where only a few edge cracks are visible. The dominant failure mode in this thickness regime consists of cracks in the inner zone of the indent. Such cracks are also observed in thicker films but appear to be less dominant as their number scales inversely with the stress transfer length $[12,14-16]$. A spiral-like morphology was observed at a load of $300 \mathrm{mN}$ and a DLC film thickness of $1.5 \mu \mathrm{m}$.

The evolution of the contact damage was analyzed by load-displacement curves and cross sections of the indents (Fig. 4). At a load of $150 \mathrm{mN}$, the load-displacement curves of the $500 \mathrm{~nm}$ and $1 \mu \mathrm{m}$ DLC films show pop-ins 


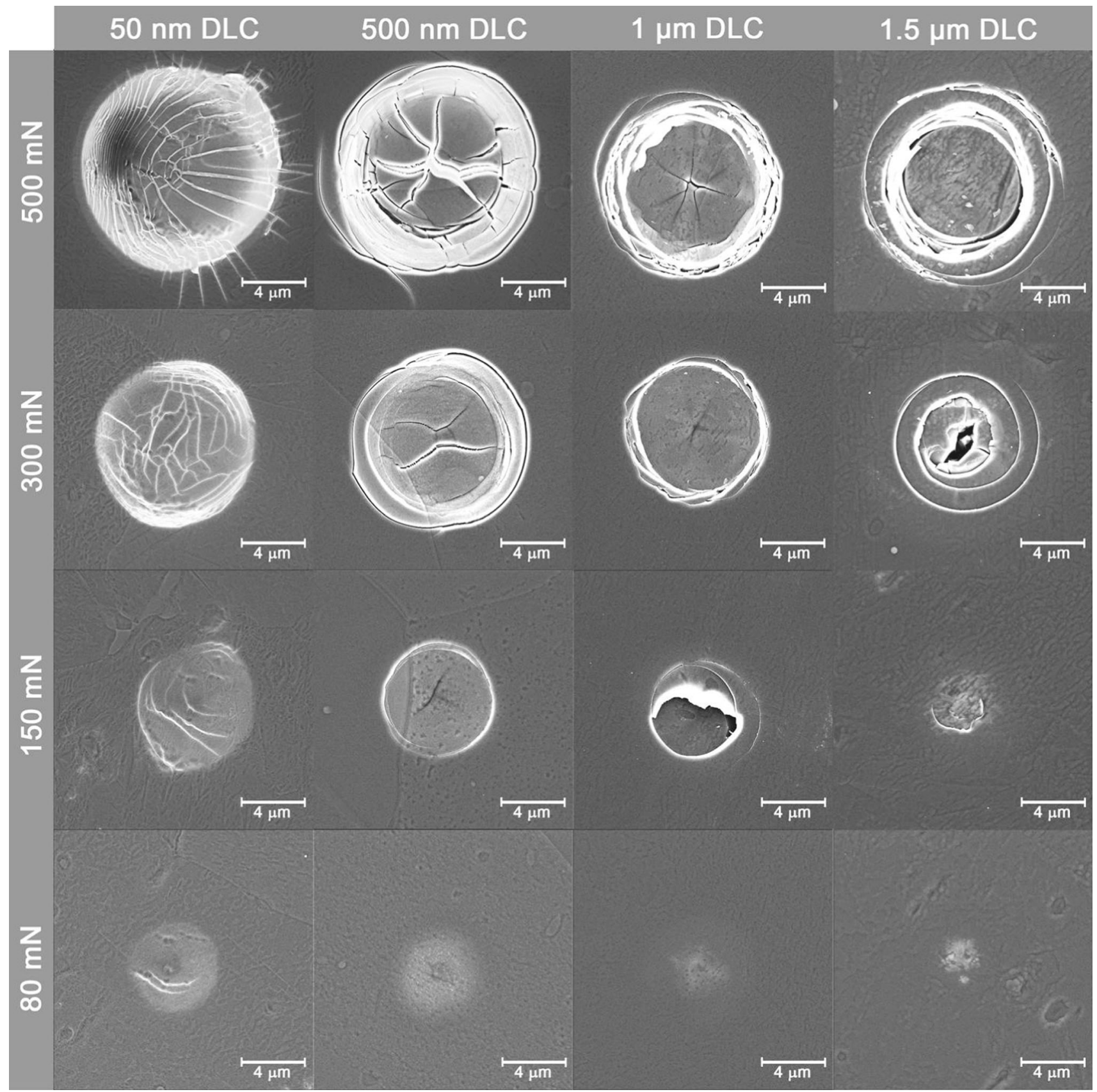

Fig. 3 Top view of the final contact damage morphology for various loads and film thicknesses taken by a secondary electron microscope

which are indicated in Fig. 4 and characterized by a discontinuity (at loads $>150 \mathrm{mN}$ more than one pop-in was present in the load-displacement curves which are not shown here). To investigate the origin of the first pop-in, cross sections of the $500 \mathrm{~nm}$ and $1 \mu \mathrm{m}$ DLC film indented with $150 \mathrm{mN}$ were examined. At a DLC film thickness of $50 \mathrm{~nm}$, no pop-in was observed even at the highest load of $500 \mathrm{mN}$, and therefore the cross section was acquired at the contact damage created with a load of $500 \mathrm{mN}$. Additionally, the comparison of the load-displacement curves shows that an increased DLC film thickness reduces the total indentation depth into the DLC-Ti structure.

The cross sections in Fig. 4 reveal that edge and interface center cracks are present in all investigated film thicknesses. From the cross sections of the $500 \mathrm{~nm}$ and $1 \mu \mathrm{m}$ DLC films, it can be concluded that the interface center crack nucleated at the Ti-DLC interface. Lateral cracks in the center of the DLC film were only observed at a film thickness of $1 \mu \mathrm{m}$. Such lateral cracks are initiated by a uniaxial stress perpendicular to the crack direction 
Fig. 4 Load-displacement curves and the corresponding cross sections for a $1 \mu \mathrm{m}$ and $500 \mathrm{~nm}$ DLC film at $150 \mathrm{mN}$ and for a $50 \mathrm{~nm}$ film at $500 \mathrm{mN}$. For film thicknesses of $1 \mu \mathrm{m}$ and $500 \mathrm{~nm}$, pop-ins in the load-displacement curves are present. Cracks at the edge and at the DLC-Ti interface are present in all three cases. Lateral cracks are only present in the $1 \mu \mathrm{m}$ DLC film
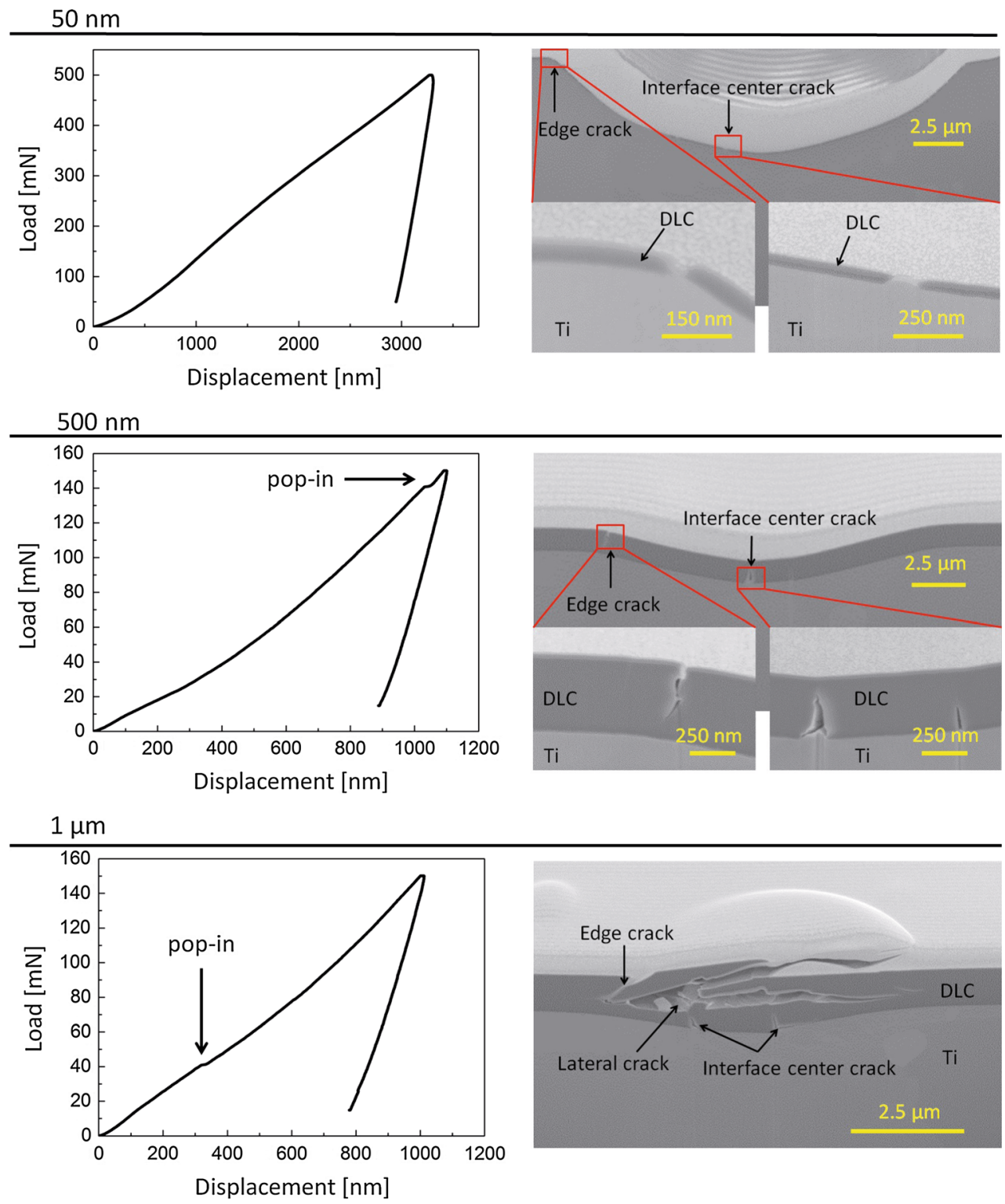

which is in the present case the out-of-plane direction and is parallel to the loading direction. This out-of-plane stress is assumed to occur during the unloading process.

\section{Discussion}

The observation from FEA that with increasing DLC film thickness an increasing load is needed to turn the surface center stress from compressive to tensile can be understood by considering the two extreme cases of very thick films and film thicknesses tending toward zero. For very thick films, the stress distribution in the film can be considered as plate-like. Thus, the stresses are compressive at the surface center and tensile at the interface center. In the other extreme case of very thin films, the plastic deformation of the Ti substrate increases the strain in the DLC film which consequently leads to overall tensile stresses in the DLC. Hence, for very thin DLC films, a membrane-like behavior [9] is present with tensile stresses at the surface center and interface center.

By comparing the stress values extracted from FEA with the stress at fracture $\sigma_{\text {fracture }}$ of the DLC film and the yield stress $\sigma_{\mathrm{y}}$ of the Ti substrate, a failure plot is generated (Fig. 5). The stress at fracture of the DLC film was determined as follows to allow for a comparison between the FEA model without prestrain and the experimental system that includes residual stresses: Up to a film thickness of $200 \mathrm{~nm}$, the stress at fracture was calculated by an adapted Griffith criterion (Eq. 1) [17], where $d$ is the 
Fig. 5 Simulated failure plot shown with the absolute loads and film thicknesses as well as with the pressure and the $d /$ $R$ ratio. The curves represent the critical load (pressure) and film thickness $(d / R$ ratio) upon the substrate yields, respectively, the location where first failure in the DLC occurs. Four zones are marked where yielding and cracking occur (or are absent) as well as exemplary micrographs are given at 80 and $300 \mathrm{mN}$ for a $50 \mathrm{~nm}$ DLC film and at 150 and $500 \mathrm{mN}$ for a $500 \mathrm{~nm}$ DLC film (indicated by crosses in the failure plot). The extracted values from FEA are represented by data points, while the corresponding fits are shown as curves

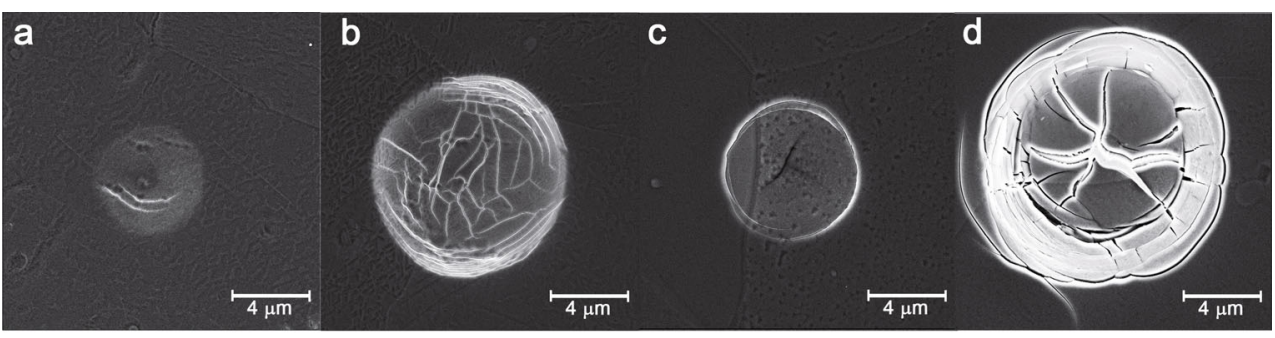

$d / R$

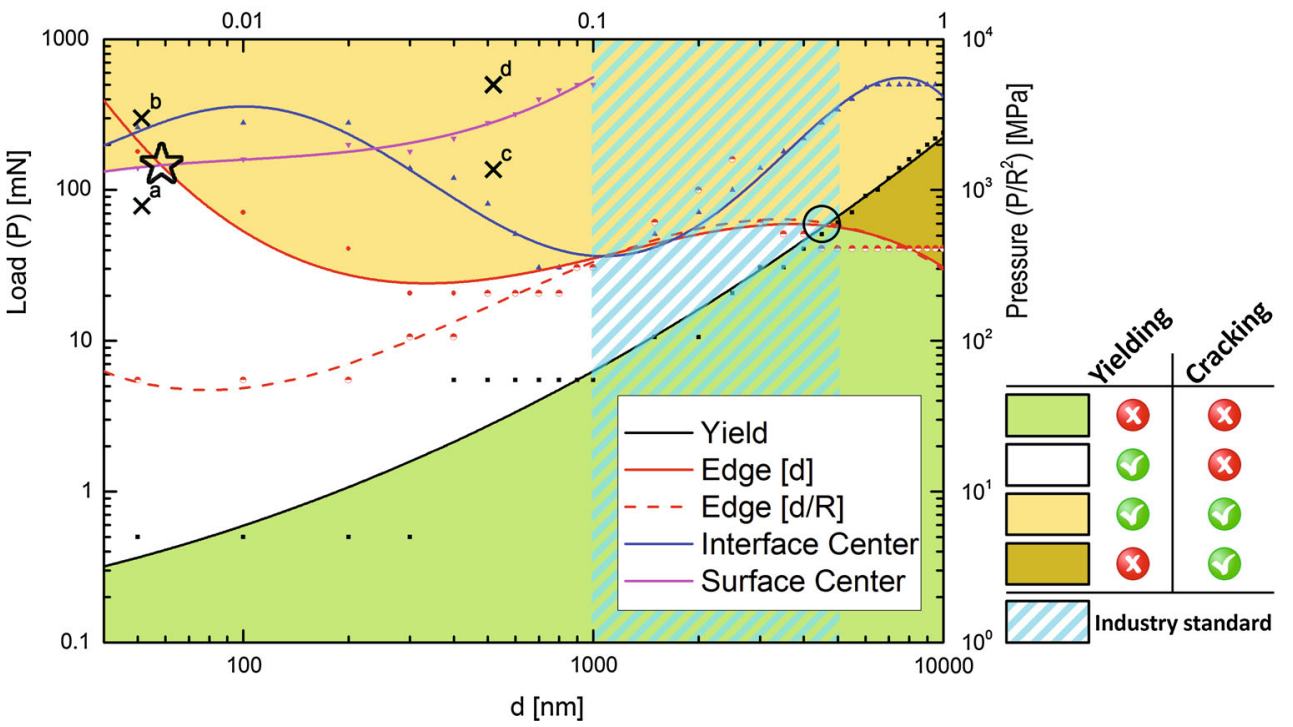

critical flaw size and assumed to be equal to the film thickness $d$, while $K_{\mathrm{IC}}$ is the fracture toughness of the DLC film. $\sigma_{\text {res }}$ represents the residual stress of $-3.8 \mathrm{GPa}$ which was taken into consideration for the stress at fracture calculation to allow for comparison to the model. The determination of the stress at fracture, calculated with the Griffith criterion up to a film thickness of $200 \mathrm{~nm}$, appears to be reasonable since crack patterns of DLC films in this thickness regime have shown to be influenced by the anisotropic deformation of the Ti substrate [12]. Thus, the maximum flaw size is comparable to the film thickness. For the fracture toughness $K_{\mathrm{IC}}$, a value of $3.2 \mathrm{MPa} \mathrm{m}^{1 / 2}$ was taken as reported in [12].

$\sigma_{\text {fracture }}=\frac{K_{\mathrm{IC}}}{\sqrt{\pi \cdot d}}-\sigma_{\mathrm{res}}$

For DLC films $>200 \mathrm{~nm}$, the stress at fracture is determined by the Hooke's law $\left(\sigma_{\text {fracture }}=E_{\mathrm{DLC}} \cdot \varepsilon_{\mathrm{on}}\right)$ with $E_{\text {DLC }}$ the Young's modulus and $\varepsilon_{\text {on }}$ the onset strain of fragmentation of the DLC. The Young's modulus of DLC is equal to $175 \mathrm{GPa}$, and the values for the onset strains of fragmentation were taken from Ref. [12] where a film thickness dependence (size effect) of the onset strain of fragmentation was reported. This behavior results subsequently in a film thickness dependence of the stress at fracture of the DLC. With the calculated film thicknessdependent stress at fracture of the DLC film and the extracted radial stresses from the FEA, the following failure criterion was applied in the failure plot in Fig. 5: crack formation in the DLC film occurs if the radial stress from the FEA exceeds the fracture stress of the DLC $\left(\sigma_{\text {radial }}>\sigma_{\text {fracture }}\right)$.

Since in the FEA the stresses in the DLC film are extracted at three different locations (Edge, Interface Center, and Surface Center), this leads to three different curves Edge [d], Interface Center, and Surface Center in the failure plot. Hence, for every film thickness (and additionally differentiated by the location), the load $P$ is known at which the DLC cracks. From this failure plot, the location of first failure can now be deduced by considering the absolute film thickness $d$ and the load $P$ (consider left and bottom axis). As the curves Edge [d], Interface Center, and Surface Center are determined with the absolute film thickness values from Ref. [12], they exhibit a film thickness behavior for very thin films.

Analogously to the failure criterion for the DLC film, the Ti substrate yields if the von Mises stress from FEA exceeds the yield stress of the $\mathrm{Ti}\left(\sigma_{\mathrm{vonMises}}>\sigma_{\mathrm{y}}\right.$, where $\sigma_{\mathrm{y}}=648 \mathrm{MPa}$ as determined in Fig. 1). The critical load needed to yield the substrate is represented by the curve 
Yield and shows that an increasing DLC film thickness increases the shielding of the substrate which is in accordance with the reduced penetration depth observed with an increasing DLC film thickness in Fig. 4.

In the FEA, the plastic deformation of the substrate is modeled with the isotropic tangent modulus $E_{\text {Tiso }}$, fitted on the engineering strain, which leads to an underestimation of the true stress-strain curve. Thus, the deformation modeled in the plastic zone of the $\mathrm{Ti}$ substrate is overestimated which results to an overestimation of the stresses in the DLC.

The failure plot shows that the location of first failure in the DLC is predominately at the edge. For very thin films, however, the three curves Edge [d], Surface Center, and Interface Center are within a very small load range, and therefore first failure cannot be predicted. This observation confirms the membrane-like behavior of thin DLC films and additionally shows that in this film, thickness regime failure is defect controlled (i.e., the film cracks at one of three locations depending on the size of a local defect).

This defect-controlled cracking can also be illustrated for DLC film thicknesses between $900 \mathrm{~nm}$ and $1.6 \mu \mathrm{m}$ where the load to initiate first failure is nearly identical at the edge and at the interface center. Thus, the location of first failure is either at the edge or interface center depending on the size and location of a defect. This statement can be rationalized by the comparison of the contact damage morphologies of 1 and $1.5 \mu \mathrm{m}$ DLC at $300 \mathrm{mN}$ in Fig. 3: Although both film thicknesses are in the regime where the appearance of edge and interface cracks is equally probable at the DLC film thickness of $1.5 \mu \mathrm{m}$, a spiral-like shape was observed while for a $1 \mu \mathrm{m}$ DLC film, edge cracks are present. The spiral-like shape arises from a propagating stress front starting from the center of the indentation, as also reported by [10], and shows that an interface center crack nucleated first, in contrast to the $1 \mu \mathrm{m}$ DLC film where an edge crack nucleated first.

From the examination of first failure and the micrographs in Fig. 3, it can be concluded that the first pop-ins in Fig. 4 were formed by edge cracks which are in accordance with $[18,19]$. The absence of pop-ins for the $50 \mathrm{~nm}$ DLC film is probably due to a lack of force and/or displacement resolution.

Furthermore, in the failure plot in Fig. 5, the following four distinct zones could be identified:

- Elastic zone (green zone): no yielding in the $\mathrm{Ti}$ substrate and no cracking in the DLC film.

- Plastic zone (white zone): yielding in the Ti substrate and no cracking in the DLC film. An exemplary micrograph is presented and denoted with $a(50 \mathrm{~nm}$ DLC at $80 \mathrm{mN})$. The crack in the micrograph is probably induced by a local defect. The corresponding location in the failure plot is indicated by a cross $\left(\mathrm{x}^{\mathrm{a}}\right)$.

- Plastic-cracking zone (bright yellow zone): yielding in Ti substrate and cracking in DLC film: Exemplary micrographs are given and denoted with $b(50 \mathrm{~nm}$ DLC at $300 \mathrm{mN}), \quad c(500 \mathrm{~nm}$ DLC at $150 \mathrm{mN})$, and $d(500 \mathrm{~nm}$ at $500 \mathrm{mN})$. The corresponding locations in the failure plot are indicated by crosses $\left(\mathrm{x}^{\mathrm{b}}, \mathrm{x}^{\mathrm{c}}, \mathrm{x}^{\mathrm{d}}\right)$.

- Elastic-cracking zone (dark yellow zone): no yielding in the Ti substrate but cracking in the DLC film for thick DLC films.

The elastic and the plastic-cracking zones (green and bright yellow zones) approach each other with increasing film thickness and finally overlap at a film thickness of around $5 \mu \mathrm{m}$ and form the elastic-cracking (dark yellow zone) zone where cracking of the DLC occurs prior to substrate yielding.

To design a contact damage-resistant system, the film and substrate should deform elastically up to the highest load possible (elastic limit). From the failure plot in Fig. 5, it can be deduced that this will be the case at a film thickness of $5 \mu \mathrm{m}$, which is indicated by a circle. An alternative way to design a crack-resistant coating system is to protect the DLC film as much as possible from fracture. This corresponds to the highest load which is not in the bright or dark yellow zone in Fig. 5 and the case at a film thickness of $60 \mathrm{~nm}$ (indicated by a star in the failure plot).

So far, the failure plot is presented with absolute loads and film thicknesses, which have been determined with an indenter radius of $10 \mu \mathrm{m}$. However, upon indentation, the stress distribution in a film-substrate combination depends on the ratio of film thickness and the indenter radius [9]. To generalize the failure plot, the curves are additionally represented by the normalized film thickness and the applied pressure. To normalize the film thickness and to determine the applied pressure, the procedure of Michler et al. [9] can be followed which shows that the film thickness $d$ and the applied load $P$ are divided by the radius $R$ of the indenter resulting to a normalized film thickness $d / R$ and an applied pressure $P / R^{2}$ (Fig. 5 top and right axis). With this generalization, the failure plot can be adapted to any film thickness and indenter radius. However, since the curves Edge [d], Surface Center, and Interface Center obey a film thickness size effect, a macroscopic failure criterion needs to be determined for the normalized film thickness $(d / R$ ratio). For this macroscopic failure criterion, the stress at fracture of a $10 \mu \mathrm{m}$ DLC film was taken. Since failure occurs in most cases at the edge, the influence of a variable $d / R$ ratio is only shown for this location and is represented by the curve Edge $[d / R]$. The curve Edge $[d / R]$ also affects the design of a contact 
damage-resistant DLC system as the highest pressure of the elastic zone and highest pressure prior to DLC cracking coincide at a $d / R$ ratio of 0.5 . Hence, if the load and particle size distribution is known, a system with an ideal DLC film thickness can be designed.

The current industry standard with DLC film thicknesses varying from 1 to $5 \mu \mathrm{m}$ is also shown in the failure plot in Fig. 5. Although this industry standard is within the range of the highest load of the elastic zone if very thin DLC films would be used almost double, the load could be applied prior to DLC film cracking (consider the logarithmic scale).

DLC is a class of material which can be deposited with variable properties [2], especially with different fracture toughness values resulting then in a changed failure behavior. In Fig. 6, this effect is shown with a fracture toughness variation from 1.7 over 4.5 to $6.0 \mathrm{MPa} \mathrm{m}{ }^{1 / 2}$ and their influence on the curves Edge [d], Interface Center, and Surface Center. These values are within a range of reported values in the literature [8, 20-22]. The fracture toughness of DLC can be varied by a different deposition procedure or by using a different precursor gas than acetylene which then forms a more polymeric-like DLC [23].

The analysis reveals that with increasing fracture toughness, the highest load of the elastic zone (green zone) increases and shifts as well to higher film thicknesses (see position change of circles in Fig. 6 upon increasing fracture toughness). In addition, the highest load, which is not in the bright or dark yellow zone (no DLC cracking), can be found at very thin DLC film thicknesses for a fracture toughness of $1.7 \mathrm{MPa} \mathrm{m}^{1 /}$ ${ }^{2}$ (indicated by the star in Fig. 6, top). However, at a fracture toughness of $4.5 \mathrm{MPa} \mathrm{m}{ }^{1 / 2}$, the highest load to avoid DLC cracking (dark and bright yellow zones) is identical for very thin DLC films (around $50 \mathrm{~nm}$ ) and at a film thickness of around $4.5 \mu \mathrm{m}$ (indicated by the two stars in Fig. 6, center). For an even higher fracture toughness of $6.0 \mathrm{MPa} \mathrm{m}^{1 / 2}$, the highest load prior to DLC film cracking shifts to a film thickness of approximately $5 \mu \mathrm{m}$. Hence, the fracture toughness affects the design of a contact damage-resistant system.

Another tunable film parameter is its intrinsic (residual) stress, which has not been treated in detail in this study. In first approximation, a variation in intrinsic stress will lead to a shift in fracture curves to a higher load or lower load for more compressive or more tensile films, respectively.

From the presented analysis, it can be concluded that the contact damage creation, evolution, and final morphology are strongly dependent on the load, the particle (indenter) size, the DLC film thickness, the elastic-plastic behavior of the substrate (which is necessary to predict contact damage on soft and ductile metallic substrates), and the mechanical properties such as fracture toughness of the DLC. By knowing these parameters, contact damage can be minimized by controlling the DLC film thickness.
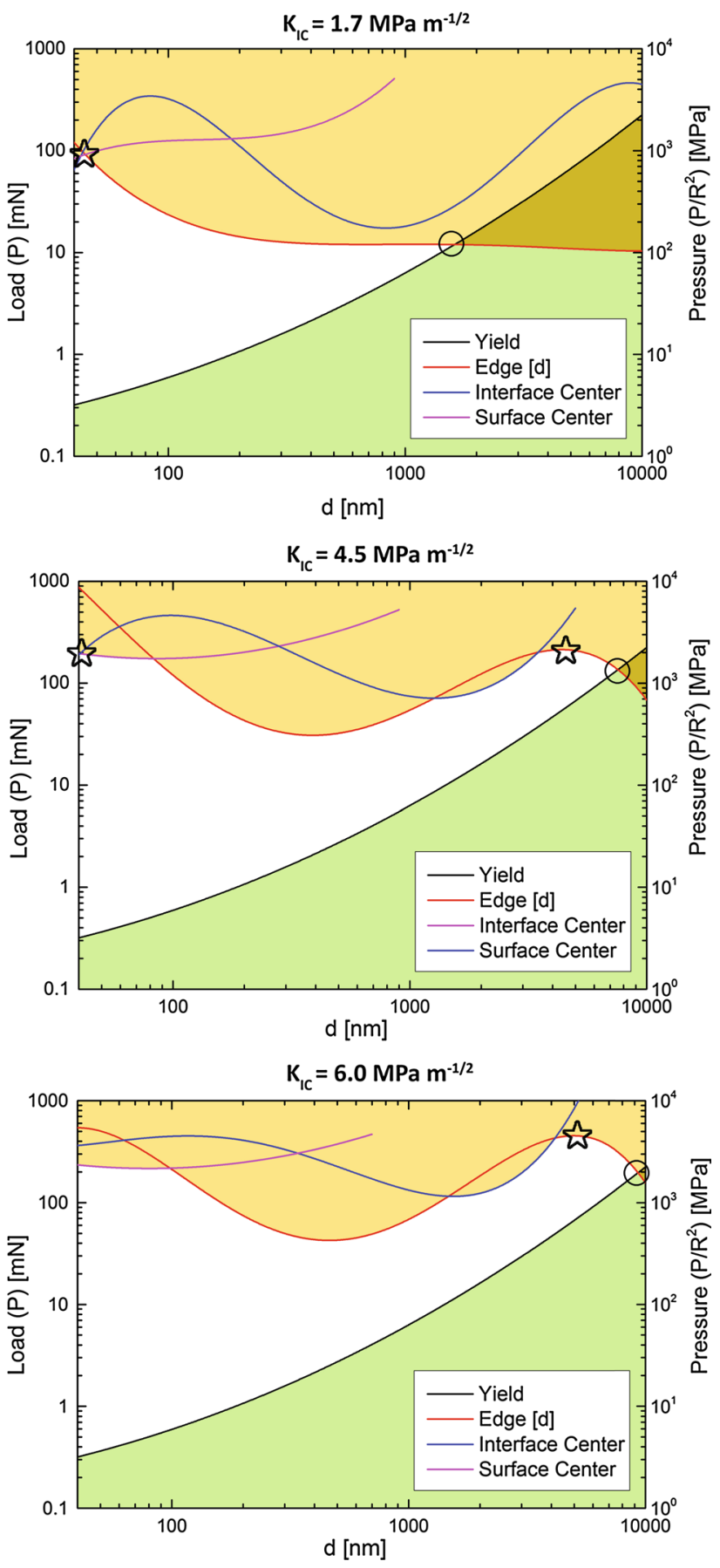

Fig. 6 The effect of the DLC fracture toughness, varying from 1.7 (top) over 4.5 (center) to $6.0 \mathrm{MPa} \mathrm{m}^{1 / 2}$ (bottom), on the zones in the failure plot (same coloring used as in Fig. 5). With increasing fracture toughness, the maximum load to retain in the elastic zone increases and also shifts to a higher DLC film thicknesses (see circles). Similarly, the maximum load (pressure), which can be applied prior to DLC film cracking, can be found, at very low film thickness $(50 \mathrm{~nm})$ for a fracture toughness of $1.7 \mathrm{MPa}{ }^{1 / 2}$, and shifts to higher values with increasing fracture toughness (see stars)

In combination with [12], the presented results lead to a film thickness optimization problem for applications of DLC films on ductile metallic substrates: On the one hand, 
thin DLC films have an increased fracture strength [12] and show no lateral cracks, while on the other hand, thicker DLC films reveal an increased resistance against plastic deformation of the substrate upon contact damage creation. Hence, to get a high fracture strength, the DLC film thickness needs to be as thin as possible, while to avoid plastic deformation upon contact damage creation, DLC film needs to be as thick as possible. Since in most tribological applications, a high fracture strength and a high resistance to plastic deformation upon contact damage creation is aimed a compromise in DLC film thickness needs to be made in order to avoid the disadvantageous properties of a too thin or too thick DLC film. This compromise requires a film thickness optimization process.

\section{Conclusion}

- Contact damage in DLC on Ti substrates was analyzed by instrumented microindentation and FEA. The DLC film thickness as well as the elastic-plastic deformation of the Ti substrate was found to significantly affect contact damage creation, evolution, and final morphology. A transition from a membrane-like to a platelike deformation was observed upon increasing the DLC film thickness.

- A failure plot could be defined with the location of first failure in the DLC and yielding of the substrate as function of the film thickness. Four distinct zones were identified where failure in DLC and $\mathrm{Ti}$ is present, respectively, where it is absent. A change in fracture toughness of DLC significantly affects the distribution of the zones in the failure plot.

- A film thickness optimization problem was presented for DLC films on ductile metallic substrates since thicker films shield plastic deformation of the substrate, while thinner films show increased fracture strength.

Acknowledgements The project is funded by the Competence Center for Materials Science and Technology (CCMX) of the ETH board, Switzerland. Financial support of DePuy Synthes GmbH, Solothurn, Switzerland is also gratefully acknowledged. The authors thank for support by the Scientific Center For Optical And Electron Microscopy (ScopeM) from ETH Zurich and Martin J. Süess from ScopeM for the realization of the FIB cross sections.

\section{References}

1. Bewilogua K, Hofmann D (2014) History of diamond-like carbon films-from first experiments to worldwide applications. Surf Coat Technol 242:214-225

2. Hauert R (2004) An overview on the tribological behavior of diamond-like carbon in technical and medical applications. Tribol Int 37:991-1003
3. Love CA, Cook RB, Harvey TJ, Dearnley PA, Wood RJK (2013) Diamond like carbon coatings for potential application in biological implants-a review. Tribol Int 63:141-150

4. Erdemir A, Donnet C (2006) Tribology of diamond-like carbon films: recent progress and future prospects. J Phys D Appl Phys 39:R311-R327

5. Schwarzer N (2000) Coating design due to analytical modelling of mechanical contact problems on multilayer systems. Surf Coat Technol 133-134:397-402

6. Doerner MF, Nix WD (1986) A method for interpreting the data from depth-sensing indentation instruments. J Mater Res 1:601-609

7. Borrero-López O, Hoffman M, Bendavid A, Martin PJ (2010) Substrate effects on the mechanical properties and contact damage of diamond-like carbon thin films. Diam Relat Mater 19:1273-1280

8. Xie ZH, Singh R, Bendavid A, Martin PJ, Munroe PR, Hoffman M (2007) Contact damage evolution in a diamond-like carbon (DLC) coating on a stainless steel substrate. Thin Solid Films 515:3196-3201

9. Michler J, Blank E (2001) Analysis of coating fracture and substrate plasticity induced by spherical indentors: diamond and diamond-like carbon layers on steel substrates. Thin Solid Films 381:119-134

10. Yonezu A, Liu L, Chen X (2008) Analysis on spiral crack in thick diamond-like carbon film subjected to spherical contact loading. Mater Sci Eng A 496:67-76

11. Fagan MJ, Park SJ, Wang L (2000) Finite element analysis of the contact stresses in diamond coatings subjected to a uniform normal load. Diam Relat Mater 9:26-36

12. Bernoulli D, Häfliger K, Thorwarth K, Thorwarth G, Hauert R, Spolenak R (2015) Cohesive and adhesive failure of hard and brittle films on ductile metallic substrates: a film thickness size effect analysis of the model system hydrogenated diamond-like carbon (a-C:H) on Ti substrates. Acta Mater 83:29-36

13. Falub CV, Thorwarth G, Affolter C, Müller U, Voisard C, Hauert $\mathrm{R}$ (2009) A quantitative in vitro method to predict the adhesion lifetime of diamond-like carbon thin films on biomedical implants. Acta Biomater 5:3086-3097

14. Cox HL (1952) The elasticity and strength of paper and other fibrous materials. Br J Appl Phys 3:72-79

15. Handge UA (2002) Analysis of a shear-lag model with nonlinear elastic stress transfer for sequential cracking of polymer coatings. J Mater Sci 37:4775-4782. doi:10.1023/A:1020814314019

16. Leterrier Y (2003) Durability of nanosized oxygen-barrier coatings on polymers. Prog Mater Sci 48:1-55

17. Griffith AA (1921) The Phenomena of Rupture an Flow in Solids. Phil Trans R Soc Lond A 221:163-198

18. Bull SJ (2005) Nanoindentation of coatings. J Phys D Appl Phys 38:R393

19. Wright T, Page TF (1992) Nanoindentation and microindentation studies of hard carbon on 304 stainless steel. Surface and Coatings Technology 54-55:557-562 Part 2:557-62

20. Wang JS, Sugimura Y, Evans AG, Tredway WK (1998) The mechanical performance of DLC films on steel substrates. Thin Solid Films 325:163-174

21. Schaufler J, Schmid C, Durst K, Göken M (2012) Determination of the interfacial strength and fracture toughness of a-C: $\mathrm{H}$ coatings by in situ microcantilever bending. Thin Solid Films 522:480-484

22. Jonnalagadda KN, Chasiotis I (2009) Strength and fracture resistance of amorphous diamond-like carbon films for MEMS. J Nanomater 2009:8

23. Robertson J (2002) Diamond-like amorphous carbon. Mater Sci Eng 37:129-281 